\title{
A DFT sight of oxygen and carbon monoxide coadsorption on Pt-alloy surfaces
}

\author{
Wahyu Tri Cahyanto ${ }^{1}$, Wahyu Widanarto ${ }^{1}$, and Hideaki Kasai ${ }^{2}$ \\ ${ }^{1}$ Department of Physics, Faculty of Science and Engineering, Jenderal Soedirman University, \\ J1. Dr. Soeparno, Karangwangkal, Purwokerto 53123, Indonesia \\ ${ }^{2}$ Department of Applied Physics, Graduate School of Engineering, Osaka University, \\ 2-1 Yamada-oka, Suita, Osaka 565-0871, Japan \\ wahyu.cahyanto@unsoed.ac.id
}

\begin{abstract}
Coadsorption of oxygen (O) and carbon monoxide (CO) on Platinum-alloy (Pt-alloy) surfaces is investigated by using density functional theory (DFT). Simultaneous coadsorption and alloying are considered in order to get more realistic picture of the electrode condition, i.e., in relation with surface CO tolerant. Significant changes on the most stable configuration for coadsorption of $\mathrm{O}$ and $\mathrm{CO}$ on PtRu- and PtRuMo-alloy surfaces to that of individual atomic $O$ or pure CO chemisorption are observed. It is found that the precovered $\mathrm{O}$ surface weakens the adsorption strength of $\mathrm{CO}$ on surfaces. However, the influence of coadsorbed $O$, i.e., bifunctional effect, is significant on monometallic Pt surface and reduces by alloying $\mathrm{Pt}$ with $\mathrm{Ru}$. Further alloy with Mo forming PtRuMo causes the bifunctional effect is very similar to that of electronic effect, i.e., pure $\mathrm{CO}$ chemisorption on PtRuMo-alloy surfaces.
\end{abstract}

Keywords- $O$ and CO Coadsorption; Pt-alloy surfaces; DFT; bifunctional and electronic effect

\section{INTRODUCTION}

One of the most important catalytic reactions and the simplest reactions is $\mathrm{CO}$ oxidation. The importance of such reaction can be seen in major reactions of car exhaust catalytic converters and issue of poisoning effects in catalysis, which is usually observed on fuel cells containing $\mathrm{CO}$ species, e.g., direct methanol fuel cells (DMFCs), or the cell designed to operate on reformed methanol. CO poisons many catalytic reactions involving transition metal active sites due to its strong bonding with such sites. Accumulation of $\mathrm{CO}$ on the catalysts thus impedes the cycle processes on the related reactions and finally reduces the device performance. Hence, it is not surprising that $\mathrm{CO}$ removal from metal catalysts by $\mathrm{CO}$ oxidation attracted many researchers to study such catalytic reactions [1-3]. A general technique to catalyze the $\mathrm{CO}$ removal from surfaces is the use of alloy catalysts such as PtRu [4] or PtNi [5] alloys, called electronic effect by alloying, which are believed to increase $\mathrm{CO}$ tolerance. Considering technological applications such as anode DMFCs, where CO is formed and further oxidized, a recent study showed that PtRuMo give better performance for this process [6]. In relation with this work, we focus on the fundamental part of $\mathrm{CO}$ oxidation, i.e., the interaction of $\mathrm{CO}+$ adsorbed oxidant with surface catalysts. It is believed that oxygen (O) responsible for facilitating $\mathrm{CO}$ oxidation [7], which is then called bifunctional mechanism.

The $\mathrm{CO}$ oxidation is one of the heterogeneous reactions and can be regarded as a benchmark system. The generally accepted mechanism of $\mathrm{CO}$ oxidation is called LangmuirHinshelwood mechanism [8]. In this mechanism, both reactants adsorb on surface followed by diffusion toward each other (or one reactant to the other) to form products, and finally the product desorption from the surface. One of the elementary reaction steps in this mechanism with respect to the $\mathrm{CO}$ oxidation is the surface reaction between $\mathrm{CO}$ and $\mathrm{O}$, i.e., the case of $\mathrm{CO}$ oxidation with $\mathrm{O}$. This $\mathrm{CO}$ oxidation resulted in desorbed carbon dioxide $\left(\mathrm{CO}_{2}\right)$. It is well known that reaction between $\mathrm{CO}$ and an adsorbed oxidant on the surface depend on adsorption energy of both species [2, 911]. Therefore, it is necessary to discuss the adsorption energy of the species under the presence of coadsorbates. In this work, we focus on the stable structure of $\mathrm{CO}$ and $\mathrm{O}$ coadsorption on $\mathrm{Pt}, \mathrm{PtRu}$, and $\mathrm{PtRuMo}$ surfaces before $\mathrm{CO}$ oxidation reaction. The role of $\mathrm{Ru}$ and $\mathrm{Mo}$ in determining the stable configuration is observed.

This paper is organized as follows. Section 2 presents computational details relevant to this work. Results mainly with regard to interaction of $\mathrm{CO} / \mathrm{O} /$ surfaces are presented in Section 3. Finally, Section 4 gives concluding remarks.

\section{COMPUTATIONAL DETAILS}

Periodic plane-wave DFT calculations are carried out to explore the coadsorption of $\mathrm{O}$ and $\mathrm{CO}$ on surfaces. The inner cores and electronic states are modeled with pseudopotentials within the framework of the projector augmented wave (PAW) method [12]. A plane wave basis set with cutoff kinetic energy of $400 \mathrm{eV}$ is used in order to get total energy convergences. A generalized gradient approximation (GGA), with the exchange-correlation functional of Perdew, Burke, and and Ernzerhof (PBE) [13, 14], is used. Brillouin-zone integration is performed by Monkhorst-Pack [15] sampling mesh of $(5 \times 5 \times 1)$ k-points using Methfessel-Paxton smearing [16] of $\sigma=0.2 \mathrm{eV}$.

We consider three surfaces, i.e., a pure Pt-, a PtRu-, and a ternary PtRuMo- surface. All these surfaces are fcc (111), represented as three layer slabs, which has been tested to be sufficient in describing $\mathrm{Pt}$ bulk system. Each slab was 
separated by a vacuum of $15 \AA$ in order to minimize the interaction among neighboring slab. Each layer is consisted of 16 atoms in a $(4 \times 4)$ unit cell. Preliminary calculation with respect to convergence test of slab thickness and kpoints is established. Geometry optimizations (relaxation) are converged to a maximum $0.05 \mathrm{eV} / \AA$ of residual atomic force. Because adsorption is made on one side of the slab, we considered also dipole moment correction through calculations [17]. Considering the $\mathrm{Pt}: \mathrm{Ru}: \mathrm{Mo}$ atomic ratio in the experiments [18] and a theoretical study of surface segregation energy of alloys' components [19] with Pt host metal; we construct alloy surfaces by substituting Pt atom on the Pt surface by $\mathrm{Ru}$ and Mo [20] which will be used as catalyst materials in this work. All calculations are performed by using the Vienna ab initio Simulation Package (VASP) [21-23].

\section{RESULTS AND DISCUSSIONS}

We use the large surface model in simulating coadsorption of $\mathrm{O}$ and $\mathrm{CO}$ since experimental results showed that $\mathrm{CO}$ is observed on $p(4 \mathrm{x} 4)$ or $p(8 \times 8)$ of $\mathrm{Pt}(111)$ surfaces at low CO coverage [24]. In the smaller cell it is reported to provide dilution to calculate the isolated $\mathrm{CO}$ adsorption energy [25]. Thus we use $(4 \times 4)$ cells with total coverage of $1 / 8 \mathrm{ML}$, i.e., the same coverage of $1 / 16 \mathrm{ML}$ for both $\mathrm{O}$ and $\mathrm{CO}$. These large unit cells are also required to provide more adsorption sites for $\mathrm{O}$ and $\mathrm{CO}$ coadsorption on binary $\mathrm{PtRu}$ and ternary PtRuMo surfaces. Both coadsorbates and all atoms in the first layer are allowed to relax in describing coadsorption processes in order to find their preferential sites. Based on previous research, interaction of $\mathrm{O}$ and $\mathrm{CO}$ is more pronounced due to the effect of surface relaxation [26]. However, under coadsorption of $\mathrm{O}$ and $\mathrm{CO}$, both of coadsorbates pull out the surface atom on which they adsorbs, the surfaces become flatter (see Fig. 1).
$\mathrm{CO}$ on $\mathrm{O} /$ surface is $1.58 \mathrm{eV}$, i.e., $0.34 \mathrm{eV}$ weaker than that of CO single molecule on Pt-surface. In our calculation, firstly, individual atomic oxygen is located at all possible adsorption sites, but it is stable only on top, hcp-, and fcc- hollow sites. At bridge site, it is unstable and tends to move to other stable site, i.e., fcc-hollow site. Our calculation shows that the most favorable site for oxygen adsorption on $\mathrm{Pt}(111)$ is the fcc, with binding energy of $4.81 \mathrm{eV}$, which is in an excellent agreement experiment [29] and other DFT calculations [26, 30]. Furthermore, on the O/Pt-surface, $\mathrm{CO}$ absorbs preferentially atop $\mathrm{Pt}$ site. The most stable position of $\mathrm{CO}$ adsorption on $\mathrm{O} / \mathrm{Pt}$-surface is different with adsorption on the clean Pt using GGA approximation, i.e., hcp-hollow site.

Alloying $\mathrm{Pt}$ with $\mathrm{Ru}$ causes the preferential binding configuration of $\mathrm{O}$ and $\mathrm{CO}$ coadsorption is changed to a position as shown in Fig. 1 (b), i.e., $\mathrm{O}$ and $\mathrm{CO}$ prefer atop $\mathrm{Ru}$ and fcc-holow site respectively. $\mathrm{CO}$ binding energy in this coadsorption system is $1.61 \mathrm{eV}$. Indeed, the coadsorption affects the weakening of $\mathrm{CO}$ binding energy by $0.26 \mathrm{eV}$ relative to the alloying effect ${ }^{[31]}$. However, our calculation shows that alloying Pt with $\mathrm{Ru}$ weakens the Pt-C interaction by $0.05 \mathrm{eV}$. This result gives smaller effect than the reduction of Pt-CO binding energy obtained by $\mathrm{Ge}$ et $\mathrm{al}^{[32]}$. This may be caused by the choice of $\mathrm{Ru}$ coverage. The oxygen adsorption site in this system is different with individual atomic oxygen adsorption on the same PtRu surface, while $\mathrm{CO}$ binding site is still maintain the original site. For individual $\mathrm{O}$ on $\mathrm{PtRu}$, the oxygen favors on bridge $\mathrm{Pt}-\mathrm{Ru}$ site, while individual $\mathrm{CO}$ molecule adsorbs on the PtPt-Pt fcc-hollow site. The calculated adsorption energy of individual atomic oxygen on $\mathrm{PtRu}$ surface is $5.16 \mathrm{eV}$. Furthermore, on the PtRuMo surface, the most favorable site for $\mathrm{O}$ and $\mathrm{CO}$ coadsorption is as depicted in Fig. 1 (c). Several possible coadsorption sites are examined, and the minimum energy of the system is obtained for $\mathrm{CO}$ atop $\mathrm{Ru}$

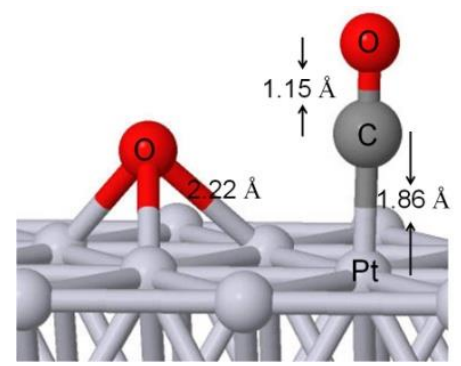

(a)

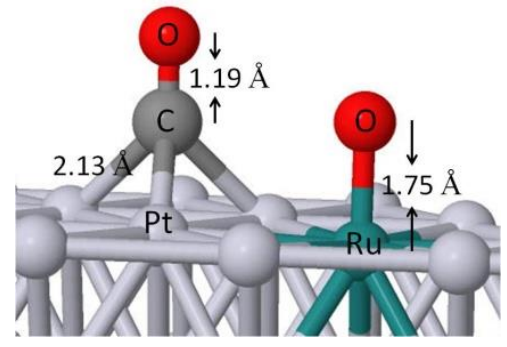

(b)

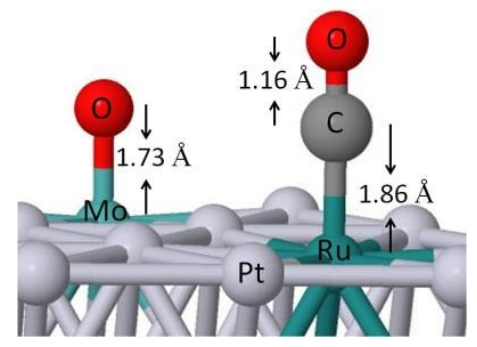

(c)

Fig. 1 The most stable configuration of $\mathrm{O}$ and $\mathrm{CO}$ coadsorption on (a) Pt, (b) PtRu, and (c) PtRuMo surfaces

Fig. 1 shows the most stable configuration of $\mathrm{O}$ and $\mathrm{CO}$ coadsorption on $\mathrm{Pt}, \mathrm{PtRu}$, and PtRuMo surfaces, i.e., structure with the minimum energy. On the pure Pt surface, the preferential sites for $\mathrm{CO}$ and $\mathrm{O}$ coadsorption are atop $\mathrm{Pt}$ and fcc site, which is in a good agreement with experiment [27] or theoretical calculation [28]. In the case of coadsorption of $\mathrm{O}$ and $\mathrm{CO}$ on surfaces, the binding energy of $\mathrm{CO}$ on O-covered surface is formulated as $E_{\mathrm{CO} / \text { surface }+\mathrm{O}}=E_{\text {tot }}$ $-\left(E_{\text {surface }+\mathrm{O}}+E_{\mathrm{CO}}\right)$, where $E_{\text {tot }}$ is the total energy of the whole system, $E_{\text {surface+o }}$ indicates the total energy of surface with individual chemisorbed $\mathrm{O}$, and $E_{\mathrm{CO}}$ represents the $\mathrm{CO}$ free energy in the gas phase. The calculated adsorption energy of and $\mathrm{O}$ atop Mo. The $\mathrm{CO}$ binding energy on $\mathrm{O}$-covered PtRuMo is $2.09 \mathrm{eV}$. This binding energy is weaker by 0.09 $\mathrm{eV}$ compared to the case of single CO molecule on PtRuMo with $\mathrm{CO}$ adsorption site moves from hollow to top $\mathrm{Ru}$ by the presence of $\mathrm{O} /$ surface. On the other hand, $\mathrm{O}$ adsorption site in the coadsorption system is not move from the original position of individual $\mathrm{O}$ on PtRuMo. Here, the adsorption energy of oxygen on PtRuMo is $5.97 \mathrm{eV}$. From the structural geometry, the shorter bond distant between $\mathrm{O}$ and surface is very apparent on the PtRuMo, indicating the stabilization of atomic $\mathrm{O}$ by Mo. 
In order to understand the $\mathrm{CO}$ chemisorptions on $\mathrm{O} /$ surfaces(111), we calculated a local density of states at $\mathrm{CO}$ from $\mathrm{Pt}-(\mathrm{O}+\mathrm{CO})$, $\mathrm{PtRu}-(\mathrm{O}+\mathrm{CO})$, and $\mathrm{PtRuMo}-(\mathrm{O}+\mathrm{CO})$. Fig. 2 displays the LDOS around $\mathrm{CO}$ on three $\mathrm{O} /$ surfaces. The solid black line represents the two $\pi$-bonds of isolated $\mathrm{CO}$ molecule. Interaction of the $2 \mathrm{p}$-states of Carbon with metal $\mathrm{d}$-states plays important role in the chemisorptions systems. Upon interactions, this state hybridized with the surface spand d-band. The two main broad peaks are observed in the presented LDOS which can be attributed to bonding and anti-bonding states.

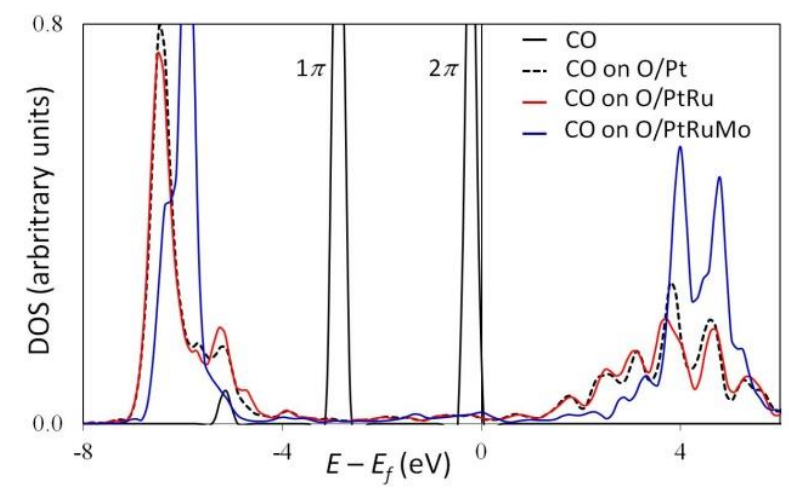

Fig. 2 LDOS around $\mathrm{CO}$ on O/surfaces

Derived anti-bonding states shifts further to right with the alloying, i.e., the position with higher energy, implying more vacant in this state caused by electron transfer to the bonding metal-C region. This explains why the bonding strength between $\mathrm{CO}$ and O/PtRuMo is higher than that of O/PtRu. Thus, compared to the LDOS of individual CO on PtRu and PtRuMo surfaces, the intensity of Mo anti-bonding states in coadsorption system is much higher than that of single molecule adsorption. This tells us less charge vacancy to be transferred to the metal-C bonding region resulting in weaker binding energy. It may be caused by atomic $\mathrm{O}$, because of its high electronegativity, withdraw some electrons. Further analysis with Bader charge difference ${ }^{[33]}$, oxygen in the coadsorption system plays significant role in withdrawing charge. In $\mathrm{CO} / \mathrm{O} / \mathrm{Pt}$, atomic $\mathrm{O}$ gets $0.70 \mathrm{e}^{-}$while $\mathrm{CO}$ is only transferred by $0.06 \mathrm{e}^{-}$of charge. Thus, in the system of $\mathrm{CO} / \mathrm{O} / \mathrm{PtRu}$, atomic $\mathrm{O}$ obtains $0.73 \mathrm{e}$, while the charge transferred to $\mathrm{CO}$ is only $0.28 \mathrm{e}^{-}$. Furthermore, $\mathrm{CO} / \mathrm{O} / \mathrm{PtRuMo}$, atomic $\mathrm{O}$ gains $1.12 \mathrm{e}^{-}$and the charge transferred to $\mathrm{CO}$ is $0.30 \mathrm{e}^{-}$. This situation may explain the bond distant of Mo-O is shorter by $0.02 \AA$ than $\mathrm{Ru}-\mathrm{O}$ in the $\mathrm{O}$ and $\mathrm{CO}$ coadsorption. In general, the presence of oxygen in the coadsorption affect more significant to the $\mathrm{CO}$ binding energy on monometallic surface, and does not weaken significantly on alloying metal surface. These results drive to the conclusion that bifunctional mechanism is more effective in the pure Pt surface.

\section{CONCLUSION}

Coadsorption of $\mathrm{O}$ and $\mathrm{CO}$ on $\mathrm{Pt}, \mathrm{PtRu}$, and PtRuMo (111) surfaces has been investigated. The most stable configuration of $\mathrm{O}+\mathrm{CO}$ on these three metal surfaces is obtained. The effect of $\mathrm{O}$ coadsorption on the weakening $\mathrm{CO}$ binding energy on the surfaces is clarified. The presence of atomic $\mathrm{O}$ may cause some electron attraction in the coadsorbed systems, resulting in the weakening CO-surfaces binding energy. However, the influence of coadsorbed $\mathrm{O}$ is significant on monometallic Pt surface and it reduces by alloying Pt with $\mathrm{Ru}$. The addition of Mo forming ternary PtRuMo surfaces causes the effect of coadsorbed O, called "bifunctional effect", is very similar to that of "electronic effect", i.e., pure CO chemisorption on PtRuMo.

\section{ACKNOWLEDGMENT}

This work is supported by Directorate General of Higher Education (DIKTI), Department of National Education, the Republic of Indonesia, through the grant of International Research Collaboration and Scientific Publication, contract No. 2086/UN23.10/PN/2014. The total energy calculation is performed by Sakura computer cluster at Kasai laboratory, Osaka University.

\section{REFERENCES}

[1] S. Gottesfeld and J. Pafford, "A new approach to the problem of carbon monoxide poisoning in fuel cells operating at low temperatures" J. Electrochem. Soc. vol. 135, pp. 2651-2652, October 1988

[2] X. Q. Gong, Z. P. Liu, R. Raval, and P. Hu, "A systematic study of $\mathrm{CO}$ oxidation on metals and metal oxides: density functional theory calculations" J. Am. Chem. Soc. vol. 126, pp. 8-9, January 2004.

[3] S. M. M. Ehteshami, and S. W. Chana, "A review of electrocatalysts with enhanced $\mathrm{CO}$ tolerance and stability for polymer electrolyte membrane fuel cells", Electrochim. Acta vol. 93, pp. 334-345, January 2013

[4] M. Watanabe and S. Motto, "Electrocatalysis by ad-atoms: Part II Enhancement of the oxidation of methanol on Platinum by Ruthenium ad-atoms" J. Electroanal. Chem. Vol. 60, pp. 267-273, April 1975

[5] W. Guo, W. Q. Tian, X. Lian, F. Liu, M. Zhou, P Xiao, Y. Zhang, “A comparison of the dominant pathways for the methanol dehydrogenation to $\mathrm{CO}$ on $\mathrm{Pt}_{7}$ and $\mathrm{Pt}_{7-\mathrm{x}} \mathrm{Ni}_{\mathrm{x}}(\mathrm{x}=1,2,3)$ bimetallic clusters: A DFT study", Computational and Theoretical Chemistry vol. 1032, pp. 73-83, January 2014.

[6] T. Y. Morante-Catacora, Y. Ishikawa, and C. R. Cabrera, "Sequential electrodeposition of Mo at Pt and PtRu methanol oxidation catalyst particles on HOPG surfaces", J. Electroanal. Chem. vol. 621, pp. 103-112, September 2008.

[7] D. Sun, X-K Gu, R. Ouyang, H-Y Su, Q. Fu, X. Bao, and W-X. Li, "Theoretical Study of the Role of a Metal-Cation Ensemble at the Oxide-Metal Boundary on CO Oxidation”, J. Phys. Chem. C vol. 116, pp. 7491-7498, March 2012.

[8] R. Imbihl, "Oscillatory reactions on single-crystal surfaces" Prog. Surf. Sci. 44, pp. 185-343, November-December 1993.

[9] C. T. Campbell, G. Ertl, H. Kuipers, and J. Segner, "A Molecular Beam Study of the Catalytic Oxidation of CO on a Pt(111) Surface", J. Chem. Phys. vol. 73, pp. 5862-5873, December 1980.

[10] M. Xu, J. Liu, and F. Zaera, "Kinetic Evidence for the Dependence of Surface Reaction Rates on the Distribution of Reactants on the Surface", J. Chem. Phys. vol. 104, pp. 8825-8828, June 1996.

[11] J. Narayanasamy, and A. B. Anderson, "Mechanism for the electrooxidation of carbon monoxide on platinum by $\mathrm{H}_{2} \mathrm{O}$. Density functional theory calculation", J. Electroanal. Chem. vol. 554, pp. 3540, September 2003.

[12] P. E. Blöchl, "Projector augmented-wave method", Phys. Rev. B vol. 50, pp. 17953-17979, December 1994. 
[13] J. P. Perdew, J. A. Chevary, S. H. Vosko, K. A. Jackson, M. R. Pederson, D. J. Singh, and C. Fiolhais, "Applications of the generalized gradient approximation for exchange and correlation", Phys. Rev. B 46, pp. 6671-6687, September 1992.

[14] J. P. Perdew, K. Burke, and M. Ernzerhof, "Generalized gradient approximation made simple", Phys. Rev. Lett. vol. 77, pp. 38653868, October 1996.

[15] H. J. Monkhorst, and J. D. Pack, "Special points for Brillouin-zone integrations", Phys. Rev. B vol. 13, pp. 5188-5192, June 1996.

[16] M. Methfessel, and A. Paxton, "High-precision sampling for Brillouin-zone integration in metals", Phys. Rev. B vol. 40, pp. 36163621, August 1989.

[17] L. Bengtsson, "Dipole correction for surface supercell calculations", Phys. Rev. B vol. 59, pp. 12301-12304, May 1999.

[18] K. R. Lee, M. K. Jeon, and S. I. Woo, "Composition optimization of $\mathrm{PtRuM} / \mathrm{C}(\mathrm{M}=\mathrm{Fe}$ and $\mathrm{Mo})$ catalysts for methanol electro-oxidation via combinatorial method", Appl. Catal. B vol. 91 pp. 428-433, September 2009.

[19] A. V. Ruban, H. L. Skriver, and J. K. Nørskov, "Surface segregation energies in transition-metal alloys", Phys. Rev. B vol. 59, pp. 1599016000, June 1999.

[20] W. T. Cahyanto, M. C. S. Escaño, R. L. Arevalo, H. Kasai, Pt(111)alloy surfaces for non-activated $\mathrm{OOH}$ dissociation, e-J. Surf. Sci. Nanotech. 9, pp. 352-356, September 2011.

[21] G. Kresse, J. Hafner, "Ab initio molecular dynamics for liquid metals”, Phys. Rev. B vol. 47, pp. 558-561, January 1993.

[22] G. Kresse, J. Furthmüller, "Efficient iterative schemes for ab initio total-energy calculations using a plane-wave basis set", Phys. Rev. B vol. 54, pp. 11169-11186, October 1996.

[23] G. Kresse, J. Furthmüller, "Efficiency of ab-initio total energy calculations for metals and semiconductors using a plane-wave basis set”, Comput. Mater. Sci. vol. 6, pp. 15-50, July 1996.
[24] M. Tüshaus, E. Schweizer, P. Hollins, and A. M. Bradshow, "Yet another vibrational study of the adsorption system Pt $\{111\}-\mathrm{CO}$ ”, J. Electron. Spectrosc. Related Phenomena vol. 44, pp. 305-316, 1987

[25] J. Yoshinobu and M. Kawai, "Thermal excitation of oxygen species as a trigger for the CO oxidation on Pt(111)", J. Chem. Phys. vol. 103, pp. 3220-3229, August 1995.

[26] B. C. Han and G. Ceder, "Effect of coadsorption and Ru alloying on the adsorption of CO on Pt", Phys. Rev. B vol. 74, pp. 205418-1205418-8, November 2006.

[27] Y. Y. Yeo, L. Vattuone, D. A. King, "Calorimetric heats for CO and oxygen adsorption and for the catalytic $\mathrm{CO}$ oxidation reaction on Pt $\{111\}$ ', J. Chem. Phys. vol. 106, pp. 392-401, January 1997.

[28] A. Sümer and A. E. Aksoylu, "CO and O coadsorption on $\mathrm{Pt}_{3} \mathrm{Sn}$ studied by DFT: Changes in the adsorptive properties of the surface with alloying and coverage", Surf. Sci. vol. 602, pp. 1636-1642, March 2008.

[29] U. Starke, N. Materer, A. Barbeiri, R. Döll, K. Heinz, M. A. Van Hove, and G. A. Somorjai, "A Low-Energy Electron Diffraction Study of Oxygen, Water, and Ice Adsorption on Pt(111)", Surf. Sci. vol. 287, pp. 432-437, May 1993.

[30] A. A. Peterson, L. C. Grabow, T. P. Brennan, B. Shong, C. Ooi, D. M. Wu, C. W. Li, A. Kushwaha, A. J. Medford, F. Mbuga, L. Li, J. K. Nørskov, "Finite-Size Effects in O and CO Adsorption for the Late Transition Metals", Top Catal. vol. 55, pp. 1276-1282, November 2012.

[31] W. T. Cahyanto, "Adsorption Mechanism of Carbon Monoxide on PtRu and PtRuMo Surfaces in the Density Functional Theory Perspective", Advanced Materials Research vol. 896, pp. 537-540, February 2014.

[32] Q. Ge, S. Desai, M. Neurock, and K. Kourtakis, "CO Adsorption on Pt-Ru Surface Alloys and on the Surface of Pt-Ru Bulk Alloy", J. Phys. Chem. B vol. 105, pp. 9533-9536, July 2001.

[33] R. Bader, Atoms in Molecules: A Quantum Theory, New York: Oxford University Press, 1990. 